\title{
TUMORS OF THE BONY CHEST WALL*
}

\author{
C. A. HEDBLOM, M.D. \\ ROCHESTER, MINN.
}

The first recorded thoracotomy for tumor was reported by Osias Aimar ${ }^{1}$ in 1778. Von Speicher, ${ }^{2}$ in 1881, reported twenty-eight cases collected from the literature, but only a few of these had been treated surgically. Parham, ${ }^{3}$ in 1898 , reported two cases of his own in which successful operations had been performed, and 101 cases from the literature. This series included the smaller series previously reported by von Speicher, ${ }^{2}$ Quénu and Longuet, ${ }^{4}$ and others. In 1913, Lund ${ }^{5}$ added twenty-seven cases to the list, including one of his own. I have found thirty-five additional cases in the literature, and twenty-three in the records of the Mayo Clinic since 1910, making a total of 188. The case reports of Gross, ${ }^{6}$ Stukkei, ${ }^{7}$ Hervy, ${ }^{8}$. Degorce, ${ }^{9}$ Palleroni, ${ }^{10}$ and Zschucke ${ }^{11}$ were not available. For statistical purposes, twentyfive cases from the Mayo Clinic in which operations were not performed are included, making 213 in all.

This classification is that of the main histologic divisions. The classification by subgroups is given in Table 2 .

Two of the cases of recurrent carcinoma were in the chest wall, following amputation of the breast in the female; two were in the male breast. One was a hypernephroma secondary to a tumor of the kidney

* From the Section on Surgery, Mayo Clinic.

1. Aimar, O.: Quoted by Parham, Footnote 3.

2. Von Speicher, S.: Quoted by Campe, G.: Ueber Tumoren der knocheren Thoraxwand, Göttingen, 1894.

3. Parham, F. W.: Thoracic Resection for Tumors Growing from the Bony Wall of the Chest, New Orleans, 1899.

4. Quénu, E. and Longuet, L.: Des tumeurs du squelette thoracique, Rev. de chir. 18:365-402, 1898.

5. Lund, F. B.: Sarcoma of the Chest Wall, Ann. Surg. 58:206-217, 1913.

6. Gross, G.: Sarcomes étendues de la région sterno-claviculaire; extirpation; autoplastic par glissement et décollement, Rev. méd. de l'est 45:497-500, 1913.

7. Stukkei, L. G.: Case of Chondrosarcoma of the Manubrium Sterni, Russk. Vrach. 14:977, 1915.

8. Hervy, M. J.: La chondrectomie (opération de Freund) est-elle une intervention bénigne? Bordeaux, Cadoret, 1915.

9. Degorce, A.: Sarcome de la paroi antero-latérale du thorax à prolongement intrathoracique, Bull. Soc. méd.-chir. de l'Indo-Chine, Hanoi and Hailfong, $5: 160,1914$.

10. Palleroni, G.: Sopra un caso di encondrosarcoma della parete toracica, Clin. med. 9:393-396, 1903.

11. Zschucke, J.: Ueber einen Fall von Myxochondrosarkom der Rippe bei einem wölfjährigen Mädchen, München, Müller and Steinicke, 1912. 
on the same side; one was secondary to a cancer of the thyroid; one was a primary epithelioma of the chest wall with involvement of the manubrium, and one was an adenocarcinoma.

It is noteworthy that while 62.4 per cent. of the cases were sarcoma, more than 8 per cent. were combinations of chondroma and sarcoma, and probably originated as chondroma.

TABLE 1.-Type of TuMOR

\begin{tabular}{|c|c|c|c|c|}
\hline $\begin{array}{l}\text { Pathologic } \\
\text { Classification }\end{array}$ & Hedblom & Parham & Lund & Total \\
\hline Chondroma & $\ldots 11$ & 25 & 4 & 40 \\
\hline Sarcoma ... & 53 & 65 & 13 & 131 \\
\hline Carcinoma & 12 & 5 & 7 & 24 \\
\hline Fibroma ... & 2 & 3 & .. & 5 \\
\hline Exostosis & 3 & & 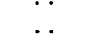 & 3 \\
\hline Gumma . & & 1 & & 1 \\
\hline Uncertain & 2 & 4 & 3 & 9 \\
\hline Total & 83 & 103 & 27 & 213 \\
\hline
\end{tabular}

Table 2.-Relative Incidence in Forty-Eight Cases: Mayo Clinic

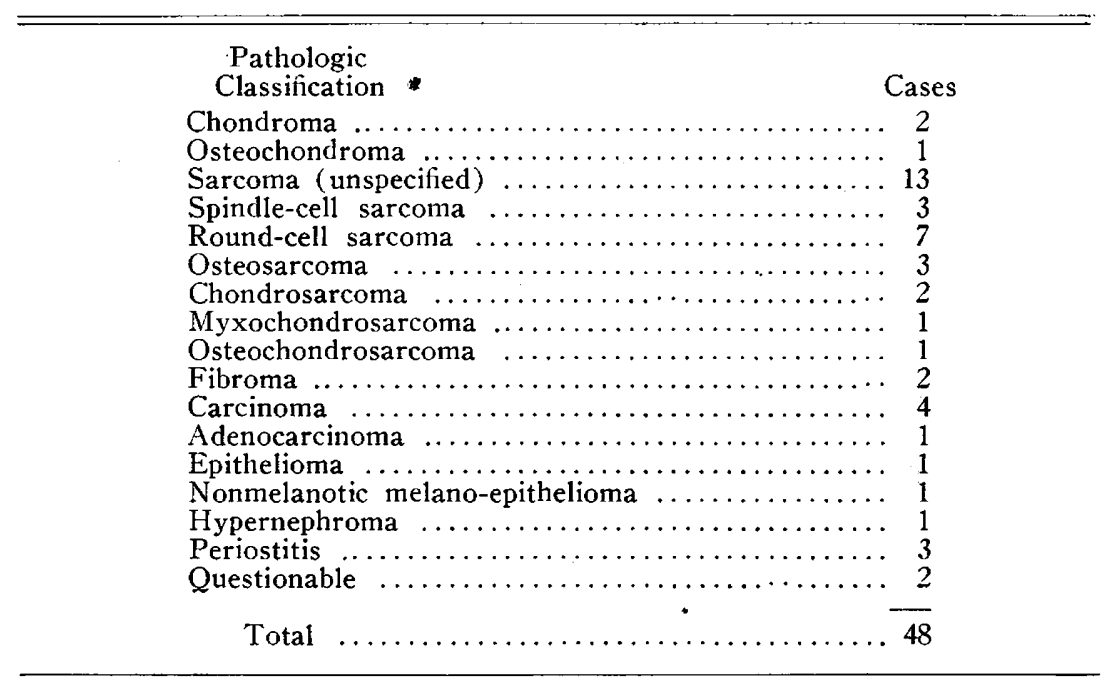

In 167 ( 78.7 per cent.) of the 213 cases, the tumors were of the ribs, and forty-six (21.3 per cent.) were of the sternum. Sixty-two and eight-tenths per cent. of the tumors of the ribs were sarcoma and 19 per cent. were chondroma. Fifty-four and three-tenths per cent. of the tumors of the sternum were sarcoma and 13 per cent. were chondroma.

In 61 per cent. of 128 cases in which location was mentioned, the right side was involved. In twenty-one of fifty-nine cases, the upper 
thorax was involved, the lower was involved in thirty-eight. The anterior aspect of the thorax was affected in thirty-two cases, the lateral in nineteen, and the posterior in eight. The first rib was involved in one case only. A single rib was affected in twenty-two cases, two ribs in twenty-two cases, three in eighteen cases, four in thirteen cases, five in four cases, and seven in one case. The manubrium appeared chiefly affected in twenty-six of the forty-one sternal cases, the gladiolus in eleven, and the xiphoid in two.

In 129 cases, the size of the tumor was variously described: as that of a hazelnut in ten; from that of an egg to that of an orange in

TABLE 3.-Age AND SeX

\begin{tabular}{|c|c|c|c|c|}
\hline Age & Hedblom & Parham & Lund & Total \\
\hline Under 10 & . 2 & 1 & & 3 \\
\hline 11 to 20 . & 8 & 13 & 4 & 25 \\
\hline 21 to 30 : & 15 & 18 & 3 & 36 \\
\hline 31 to 40 & 16 & 21 & 2 & 39 \\
\hline 41 to 50 & 11 & 14 & 3 & 28 \\
\hline 51 to 60 & 13 & 19 & 1 & 33 \\
\hline 61 to 70 & 13 & 1 & 1 & 15 \\
\hline $\begin{array}{l}71 \text { to } 80 \\
\text { Not stated }\end{array}$ & $\begin{array}{l}2 \\
3\end{array}$ & 16 & 13 & $\begin{array}{r}2 \\
32\end{array}$ \\
\hline Total & 83 & 103 & 27 & 213 \\
\hline Sex & Hedblom & Parham & Lund & Total \\
\hline Males. & . 48 & 61 & 7 & $116(62.3 \%)$ \\
\hline Females & 35 & 32 & 3 & 70 \\
\hline Not stated & . $\quad$. & 10 & 17 & 27 \\
\hline Total & 83 & 103 & 27 & 213 \\
\hline
\end{tabular}

TABLE 4.-DURATion OF TUMOR

\begin{tabular}{rcc}
\hline & Chondroma & Sarcoma \\
Less than one year $\ldots \ldots \ldots$ & $6(23 \%)$ & $38(34.5 \%)$ \\
One to six years $\ldots \ldots \ldots$ & $12(46 \%)$ & $60(54.5 \%)$ \\
More than six years........ & $8(31 \%)$ & $12(10.9 \%)$ \\
Total $\ldots \ldots \ldots \ldots \ldots$ & $\frac{12}{26}$ & 110 \\
\hline
\end{tabular}

seventy-two, and from that of a grapefruit to that of an adult head in forty-seven. In the Mayo Clinic and collected series three were from $1 \mathrm{~cm}$. to $2 \mathrm{~cm}$. in diameter, thirty-eight from $5 \mathrm{~cm}$. to $12 \mathrm{~cm}$, and seventeen from $15 \mathrm{~cm}$. to $30 \mathrm{~cm}$.

The tumor had been present in about 39 per cent. of the 126 cases less than one year, and in about 74 per cent. less than four years.

\section{ETIOLOGY}

There usually is no history of trauma in tumors of the chest wall, but the absence of such a history is not conclusive proof that the origin 
was not traumatic. Minor injuries, as a rule, are quickly forgotten. Furthermore, chest tumors are more common in males, who are more subject to trauma, and the area involved is usually the more exposed anterior or lateral portion of the chest. Thus, of the cases in this series in which sex and site were specified, the tumor occurred in males in more than 62 per cent., on the right side in 60 per cent., and on the exposed upper anterior part of the chest in more than 85 per cent.

The apparent influence of trauma on the development of a tumor, which, however, may remain small and apparently dormant for some time, is well illustrated by Cases $3,12,13$ and 14 . The apparent accelerating effect of secondary trauma and of operation when complete extirpation was not attained is a striking finding in Cases 2, 7, and 14.

Amburger ${ }^{12}$ and Tietze ${ }^{13}$ report cases in which the growth followed pregnancy, and in Tietze's case the tumor grew in three periods following three successive pregnancies during nine years.

\section{SYMPTOMATOLOGY}

Aside from the presence of a tumor, pain is the most characteristic symptom. Some degree of soreness or pain was present in 50 per cent. of my personal and collected cases. Loss of weight was noted in fifteen ( 31.2 per cent.). Dyspnea was present in only four, and effusion in two.

In many cases, pain is present before there is any discernible growth, as in my Case 10 and the cases reported by Hesse, ${ }^{14}$ Sourdille, ${ }^{15}$ Busse, ${ }^{16}$ and others. This may be accounted for by the fact that in some instances the growth begins on the pleural aspect and early infiltrates the pleura and involves the intercostal nerves. Busse reports a case of myxochondrosarcoma originating in the pleura and encroaching exclusively on the pleural cavity, causing great pain and dyspnea, and finally death. A painless tumor may be present for years, and then suddenly become very painful (Case 9). The onset of pain may be incident to sarcomatous degeneration, but a chondroma may also be painful. The unreliability of this symptom as a criterion in the differential diagnosis of malignancy is shown by the fact that while pain

12. Amburger, N.: Zur operativen Behandlung der Brustwand- und Mediastinalgeschwülste, Beitr. z. klin. Chir. 30:770-804, 1901.

13. Tietze, A.: Beiträge zur Resection der Thoraxwandungen bei Geschwülsten, Deutsch. Ztschr. f. Chir. 32:424-437, 1891.

14. Hesse, O.: Beitrag zur Differential-diagnose der Thoraxtumoren. Fortschr. a. d. Geb. d. Roentgenstrahlen 18:246-256, 1911-1912.

15. Sourdille, G.: Ostéosarcome des côtes cher. un enfant de 11 ans, Gaz. méd. de Nantes 27:31-33, 1909.

16. Busse, O.: Ueber ein Chondro-Myxo-Sarcoma pleurae dextrae, Virchows Arch. f. path. Anat. u. Physiol. 189:1-11, 1907. 
was present in thirty-four of forty-nine cases of sarcoma (almost 70 per cent.) in my own and Parham's series, it was present in five of twelve cases of chondroma.

The physical examination gives little evidence of the nature of the tumor. A smooth surface is characteristic of chondroma, a nodular irregular surface, of sarcoma; but inasmuch as sarcoma frequently develops in chondroma, this finding is always of uncertain value. Enlarged regional glands are present only occasionally.

\section{DIAGNOSIS}

In typical well advanced cases, the diagnosis of neoplasm is certain ; but in early cases, a definite diagnosis may be impossible. Cold abscess, exostosis, gumma, aneurysm, and dermoid cyst must be differentiated. Derynzhinski ${ }^{17}$ and Walther ${ }^{18}$ report resection of the chest wall for deep seated lipoma simulating sarcoma. Cases that at operation prove to be inflammatory may have a history typical of neoplasm (Case 1). Pulsating sarcoma may simulate aneurysm. Exostosis may be impossible to differentiate in the early stage without an exploratory operation (Cases 4, 5 and 6). In case of a deep seated tumor, particularly beneath the heavy muscles posteriorly, there may be no external tumor, as in the cases reported by Lejars, ${ }^{19}$ Baldwin ${ }^{20}$ and Matry, ${ }^{21}$ and as has been noted, there may be only pain, and possibly loss of weight. Such cases are often diagnosed intercostal neuralgia. A case of a tumor developing under the female breast is reported by Amburger. Dermoid cysts of the sternum are reported by Bird, ${ }^{22}$ Calvalcanti, ${ }^{23}$ and others. The differentiation of types of neoplasm is also uncertain, particularly on account of the tendency to malignant degeneration of the benign forms. It may also be impossible to distinguish between a primary and a metastatic growth (Case 10).

\section{TREATMENT}

Early radical extirpation has been generally accepted as the treatment of choice. The accepted indications and contraindications to

17. Derynzhinski, S. F.: Excision of a Considerable Portion of the Thorax Together with the Pleura for Primary, Very Rare Tumor of the Rib, Ending in Recovery, Khirurgia, Mosk 15:417-423, 1904.

18. Walther, C.: Lipome périostique congénital de la paroi costale, Bull. et mém. Soc. de Chir. de Par. 40:367-370, 1914.

19. Lejars, F.: Les tumeurs, de siège anormal, du squelette thoracique, Semaine méd. 34:16, 1914.

20. Baldwin, J. F.: Sarcoma of the Chest Wall, Ann. Surg. 58:853-855, 1913.

21. Matry: Quoted by Lejars, Footnote 19.

22. Bird, A. C.: A Case of Dermoid Cyst of the Sternum, Lancet 2:1215, 1904.

23. Cavalcanti, M.: Observation sur un cas de kyste dermoïde préexternal, Tr. Internat. Cong. Med. 1913, London, 1914, Sect. vii, Surg, Pt. 2, 219. 
operation, however, have been various, depending chiefly on considerations of operative pneumothorax, proneness to recurrence in case of malignant tumors, and supposed innocuous nature of tumors considered benign.

A radical operation was performed in ten of the forty-eight cases in the Mayo Clinic; a more or less palliative excision with cautery was performed in thirteen. One patient refused operation. The remaining twenty-four were considered inoperable. In one case of the first group (Case 10), the excised tumor was found to be an adenocarcinoma. No evidence was elicited before or after operation of a primary tumor elsewhere. Necropsy six months after operation, however, revealed a primary growth in the suprarenals. This is an example of an absolute but unrecognizable contraindication to operation. Of the thirteen cases in which a less extensive operation was performed, there was roentgen-ray evidence of metastasis in four; three were cases of carcinoma with extensive infiltration. One patient was four months pregnant. In the remaining five cases, the tumor was excised and cautery applied; but the operation was less extensive than in the first group, and in no case was the pleural cavity opened.

In the group of twenty-five patients not operated on, tissue was removed for biopsy in fourteen. One patient refused operation. There was roentgen-ray evidence of metastasis in eleven. Two patients had carcinoma. Four tumors were diagnosed inflammatory by microscopic examination; three were periostitis. In six cases, the condition was considered too extensive for excision, and one patient was in too poor condition to withstand operation.

Many of these patients, operated on and not operated on, had radium and roentgen-ray treatment; most of them after operation only, but some before operation as well as after, but without definite permanent cure, so far as is known. Marsh, ${ }^{24}$ Turner ${ }^{25}$ and others report cases apparently cured by radiotherapy.

The contraindications to radical operation in this group were metastasis, very extensive involvement in a case of sarcoma and chondroma, deeply infiltrating carcinoma, periostitis, and advanced cachexia. The diagnosis of metastasis may be erroneous. In one instance in this series, the roentgen ray revealed apparent involvement of the upper lobe of the lung. The patient, however, is alive after more than three years. The tumor of the chest wall has grown to enormous proportions; but nothing has developed to substantiate the early diagnosis of metastasis.

24. Marsh, J. P.: A Case of Supposed Sarcoma of the Chest Wall Symptomatically Cured by Means of the X-Ray, Am. J. M. Sc. 127:1055-1056, 1904.

25. Turner, D.: A Case of Myeloma of the Sternum Treated by Radium, Brit. M. J. 2:218, 1915. 
When there is uncertainty as to metastasis, the finding of BenceJones protein in the urine may be confirmatory. In two instances in this series in which the urine contained Bence-Jones protein, there was multiple metastasis in the bones. One was a case of chondroma of long standing (Lemon,"6) the other a case of round-cell sarcoma in which the roentgen ray revealed multiple unsuspected metastases in the skull and pelvic bones.

The cases found at operation to be inflammatory are examples of a relative indication for operation, as an early diagnosis could not be made by other means.

The operability of carcinoma involving the chest wall is probably at best doubtful. Schede ${ }^{27}$ exhibited a case symptom-free one year after operation for recurrence following breast amputation. Sauerbruch ${ }^{28}$ uses the opposite breast dissected free from the pectoral fascia and with a wide pedicle to cover over the defect after breast amputation with resection of the chest wall. Fink ${ }^{29}$ reported a case free from recurrence three and three-fourths years after resection. A few other cases with apparent cure have been reported.

Extensive infiltration with involvement of adjacent structures is not considered a contraindication by some surgeons. In my collected series, portions of the diaphragm were removed in six cases. One patient died after operation, the other five had recurrences. The transverse process of one vertebra was removed in one, but the tumor recurred. In one instance reported by Amburger, ${ }^{12}$ the clavicle, the first and second ribs, and the sternum were resected, and both pleural cavities were opened. The patient died the third day after the operation, cause not stated. Mayer ${ }^{30}$ opened both pleural cavities in resecting the sternum; the patient died the ninth day of empyema. Ligation of the jugular veins and the suture of a tear in the innominate vein is reported by Lanphear ${ }^{31}$ in a case of resection of the sternum.

In Lund's ${ }^{5}$ series the diaphragm was injured in six cases, with postoperative recovery. In one case the pericardium was opened with operative recovery. In one case (Lockwood ${ }^{32}$ ) the diaphragm, pericardium, and part of the lung were resected, but recurrence followed.

26. Lemon, W. S.: Chondroma of the Thorax, Journal-Lancet 39:59-60 (Feb. 1) 1919 .

27. Schede: Mammacarcinom, Deutsch. med. Wchnschr. 12:646, 1886.

28. Sauerbruch, F.: Die Chirurgie der Brtstorgane. Berlin, Springer, 1920.

29. Fink: Quoted by Amburger, Footnote 12.

30. Mayer: Sarcome du sternum, J. méd. de Brux. 9:146, 1904.

31. Lanphear, E.: Removal of Sternum for Cancer with Suturing of the Innominate Vein; Surg., Gynec. and Obst. 14:619-622, 1912.

32. Lockwood, C. B.: On the Excision of Tumours of the Chest-Wall, Clin. Jour. 30:369-374, 1907. 
Rixford ${ }^{33}$ excised the first rib, clavicle, and sternum, and the patient recovered. Torek ${ }^{34}$ excised a portion of the lung, but the patient died from shock. The end-result is not stated for any of the patients who survived the operation.

In five of eleven cases cited by Amburger, in which the lung was resected with the tumor, a cure resulted (Péan, ${ }^{35}$ Müller, ${ }^{36}$ and Krönlein ${ }^{37}$ ) ; but in one (Krönlein ${ }^{38}$ ) a second lung resection was necessary. The patient died seven years later of further recurrence. Péan's patient was free from recurrence after one year. Krause ${ }^{39}$ resected a portion of the lung in two cases of carcinoma. There was freedom from recurrence eight and eighteen months later, respectively. Helfrich ${ }^{40}$ performed a lobectomy in one case; but the patient died twenty-four hours later of cardiac failure. One patient operated on by Mikulicz ${ }^{41}$ in whom the diaphragm was resected remained free from recurrence for fourteen months. Several other cases are recorded; all the patients eventually died of recurrence. Judging from these results it seems that although involvement of the diaphragm, pericardium, and lung is not a contraindication to operation, the result of operation can probably be regarded, almost without exception, as palliative only.

\section{OPERATIVE TECHNIC}

The prevention of pneumothorax and combating its immediate harmful effects have been the chief considerations in operating. Great divergence of opinion and of experience has existed with regard to the harmfulness of pneumothorax and of the advantages of differential pressure anesthesia. In the earlier operations, attempts were always made to excise the tumor without opening the pleura, and thus prevent pneumothorax. In twenty-six of Parham's ${ }^{3}$ eighty-two cases, the pleural cavity was not opened. When it was opened, obturating the opening with gauze tampons, immediate suture of the pleura, suture of the lung to the edges of the tumor-bearing area, and closure

33. Rixford. E.: Excision of Portions of the Chest Wall for Malignant Tumors, Ann. Surg. 43:35-47, 1906.

34. Torek, F.: Resection of a Large Portion of the Chest Wall for Sarcoma, Post-Graduate, New York 21 :335-337, 1906.

35. Péan, J. E.: Quoted by Amburger, Footnote 12.

36. Müller, W.: Eine Thoraxwand-Lungenresection mit günstigen Verlauf, Deutsch. Ztschr. f. Chir. 37:41-49, 1893.

37. Krönlein: Ueber Lungenchirurgie, Berl. klin. Wchnschr. 21:129-132, 1884.

38. Krönlein: Ueber Lungenchirurgie, Berl. klin. Wchnschr. 23:185, 1886.

39. Krause: Quoted by Amburger, Footnote 12.

40. Helfrich: Quoted by Amburger, Footnote 12.

41. Mikulicz: Reported by von Noorde, W.: Zur Operation der grossen Chondrome des Rumpfes; ein Beitrag zur Chirurgie des Zwerchfelles, Deutsch. med. Wchnschr. 19:346-349, 1893. 
of the skin flap were the most common methods of combating the harmful effects. Witzel ${ }^{42}$ changed pneumothorax into hydrothorax, then aspirated the fluid. Dollinger ${ }^{43}$ gradually induced collapse of the lung by admitting air through a small opening in the pleura before the day of operation and Beccherle ${ }^{44}$ at the time of resection. Artificial respiration through intubation or tracheotomy was recommended (Doyen, ${ }^{45}$ Tuffier, ${ }^{46}$ Hallem, ${ }^{47}$ Quénu and Longuet, ${ }^{48}$ and others). Parham ${ }^{3}$ used the Fell-O'Dwyer apparatus in one case, with satisfaction. Then followed Meltzer's intratracheal insufflation, Sauerbruch's and Meyer's differential pressure chamber apparatus, and finally the recognition that a simple intrapharyngeal insufflation can be used with apparently equally good results. Sauerbruch ${ }^{28}$ writes that differential pressure is probably never so particularly indicated as in cases of extensive resection of the thorax.

\section{PNEU MOT HORAX}

In five of ten cases in the Mayo Clinic, the pleura was opened, in all without differential pressure. There were no immediate alarming symptoms in any case; but there was marked postoperative shock in one case and moderate shock in two cases. In the others there were practically no symptoms. In the five in which the pleura was not opened, there was marked postoperative shock in three, and little or no shock, in two.

In the collected cases, the pleura was opened in twenty-four cases, not opened in five cases, and the procedure not stated in six cases. Differential pressure was used in five of the twenty-four cases. There was postoperative shock in one case. There was shock in four of the cases not under differential pressure, and in one in the group of five cases in which the pleura was not opened. Five of the six patients who died as a result of operation had had the pleura opened without differential pressure. Two of these patients showed marked postoperative shock. Three patients died from empyema, one from shock and anuria, one from cardiac collapse, and one three days after operation, cause of death not stated. In eighteen of Lund's cases in which the facts are specified, five operations were performed with differential

42. Witzel, O.: Ein Verfahren zur Beseitigung des akuten nach Penetration der Brustwand entstandenen Pneumothorax, Centralbl. f. Chir. 17:523-526, 1890.

43. Dollinger: Quoted by Lund, Footnote 5.

44. Beccherle, G.: Condroma costale; ampia resezione toraco-pleurica, guarigione, Cesalpino, Arezzo 10:204-217, 1914.

45. Doyen: Quoted by Amburger, Footnote 12.

46. Tuffier: Quoted by Amburger, Footnote 12.

47. Hallem: Quoted by Amburger, Footnote 12.

48. Quénu, E., and Longuet, L.: Recherches expérimentales et étude critique sur la chirurgie du poumon, Bull. et mém. Soc. de Chir. 22:787-795, 1896. 
pressure and thirteen without. One patient operated on under positive pressure and three without pressure had had severe shock. One patient who died from shock was operated on without differential pressure. One patient operated on under positive pressure died the fourteenth day of pneumonia.

Parham states that in forty-one cases in which operation was performed without differential pressure there was little or no disturbance in sixteen, moderate disturbance in ten, and severe disturbance in fifteen. There can be no doubt that serere shock may develop as a result of operation and entirely independent of pneumothorax. This was especially noticeable in Case 9 and in Case 10; both patients were debilitated and had been subjected to wide excision of a large tumor without pneumothorax.

An operation in two or more stages extends the limits of operability and lowers the postoperative shock. Such an operation can be performed under local anesthesia, and if the lung is sutured to the parietal pleura at the first stage, pneumothorax is prevented without the use of positive pressure anesthesia. Such a procedure probably represents the minimum of risk to the patient. Intrapharyngeal insufflation anesthesia seems, however, the simplest and generally the most satisfactory method. Tight closure of the chest is essential. In one case (Case 8) the skin sloughed at the suture line, producing an infection necessitating a secondary plastic operation.

Even following wide excision there appears to be no untoward effect from the absence of ribs and intercostal tissue. Mayer, ${ }^{30}$ however, reports a case in which a hernia of the lung followed. Kirschner ${ }^{49}$ reports two cases in which, following extensive resection, he sutured a flap of fascia lata from the thigh into the window in the chest wall with good results.

There was one immediate operative death in the Mayo Clinic series (less than 5 per cent.). There were eleven deaths in the eightyfive cases since 1898 (about 13 per cent.).

In Parham's series there were thirty deaths in 103 cases (29 per cent.). The cause of the sixteen deaths in the fifty-five cases in which the pleura was opened was shock in seven, empyema in two, hemorrhage and sepsis in five, "bronchitis" in one, and phenol poisoning in one; the cause of death in the remaining two cases was uncertain.

Of the sixteen patients in the Mayo Clinic series with recurrence, eleven are dead. One of the two patients without recurrence had excision of a sarcoma and cauterization without the opening of the pleura. He has remained symptom-free for eight and one-half years.

49. Kirschner, M.: Der gegenwärtige Stand und die nächsten Aussichten der autoplastischen, freien Fascien- Uehertragung. Beitr. z. klin. Chir. 86:5-149, 1913. 
The other, a patient with fibroma, has remained symptom-free more than nine years. Six of the twenty-one patients had operations for recurrence, one three years after the primary operation; this patient has remained symptom-free one year after the second operation. Of the other five patients one was reoperated on four times, three twice, and two once. Two had been operated on the first time elsewhere.

Table 5.-Cause of Drath in the Three Groups

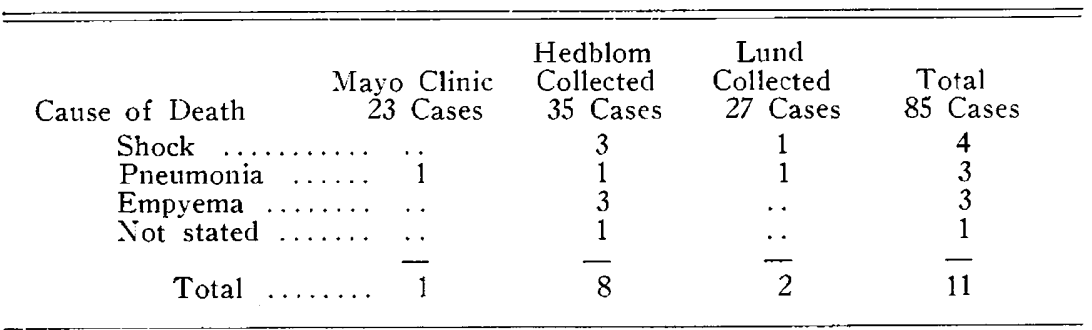

TABLE 6.-RECURRENCE

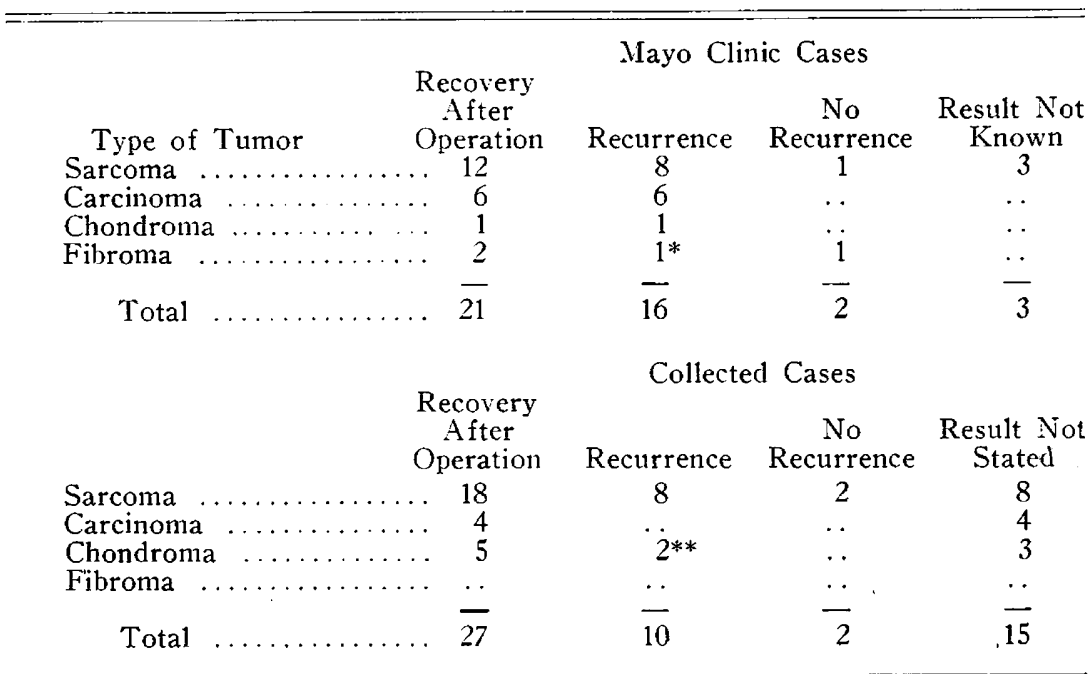

*Operation for recurrence; no further recurrence after one year.

** Recurrence in one case following extirpation; end-result not known.

One patient, aged 38, came to the clinic with a history of having had an operation for sarcoma of the lower anterior chest wall at the age of 6 and operations for recurrences at the ages of 27,36 and 37 . He presented himself with a large ulcerating area, but there was no definite tumor. A roentgenogram showed a shadow which was interpreted as metastasis in the lung; microscopic examination showed sarcoma. Cases 12 and 14 are examples of long freedom from recurrence. Case 7 is an example of very rapid malignant growth. 
In the thirty-five collected cases, there were twenty-seven postoperative recoveries. The end-results, after one year, are given in twelve cases; in two cases there were no symptoms for two and one-sixth years and seven years, respectively, after operation.

In Parham's series of twenty-five cases of sarcoma, eight patients were free from recurrence from one to five years, and two of seven patients with chondroma were free from recurrence one and five years, respectively.

In the total sixty-five cases, then, in which results were ascertained after one year, only fifteen patients ( 23 per cent.) remained free from recurrence at the time of the last report. This shows that the tendency to recurrence is great, not only of sarcoma but also of the so-called benign chondroma and fibroma. It may be noted that there was no known recurrence in seven of thirteen cases of chondroma; but there was recurrence in one after six years.

It seems evident, from these considerations, that the large majority of malignant growths of the chest wall may be expected to recur or metastasize after excision, and that the so-called benign growths are liable to do so. It seems equally clear that extirpation of the tumor prolongs life materially in most instances even when the operation is performed late or for extensive involvement or for repeated recurrence.

\section{SUM MARY}

1. Tumors of the bony chest wall are relatively rare. In 213 cases (61.4 per cent. sarcoma and 18.7 per cent. chondroma) the ribs were primarily involved in 78.7 per cent., and the sternum in 21.3 per cent.

2. Trauma seems to be etiologic in some cases, both with regard to incidence and to malignant degeneration of the benign forms.

3. Pain is the most characteristic symptom and may be present in the case of a benign as well as of a malignant tumor. Pain may be present before the tumor is recognized.

4. Early differential diagnosis of neoplasm and cold abscess, exostosis, aneurysm, and dermoid cyst may be difficult. Preoperative differentiation of a benign or a malignant neoplasm may be impossible.

5. Early radical extirpation offers the best prospect of prolonging life and of cure. Late radical or palliative extirpation, even in the presence of extensive involvement, may result in a relatively long period of freedom from recurrence.

6. Early exploratory thoracotomy is indicated in any doubtful case.

7. Differential pressure anesthesia, while not essential to the successful removal of tumors involving wide opening of the pleural cavity, obviates the risk incident to sudden open pneumothorax, and by preventing a closed pneumothorax may lessen materially the occurrence of postoperative shock, pneumonia, and empyema. 
8. Intratracheal or intrapharyngeal insufflation anethesia affords an effective means of preventing operative pneumothorax.

9. Shock, pneumonia, and empyema are the common causes of postoperative deaths.

10. Recurrence has been the rule in most cases of malignant tumor; but there may be freedom from recurrence for many years and life may be further prolonged by repeated extirpation of the growth.

\section{REPORT OF CASES}

Case 1 and Cases 4 to 14, inclusive, are those in which radical extirpation of the tumor was attempted. Case 1 is too recent to be included in the series, but it is classified with Cases 2, 3, and 4 as an inflammatory tumor presenting special difficulties in diagnosis. In

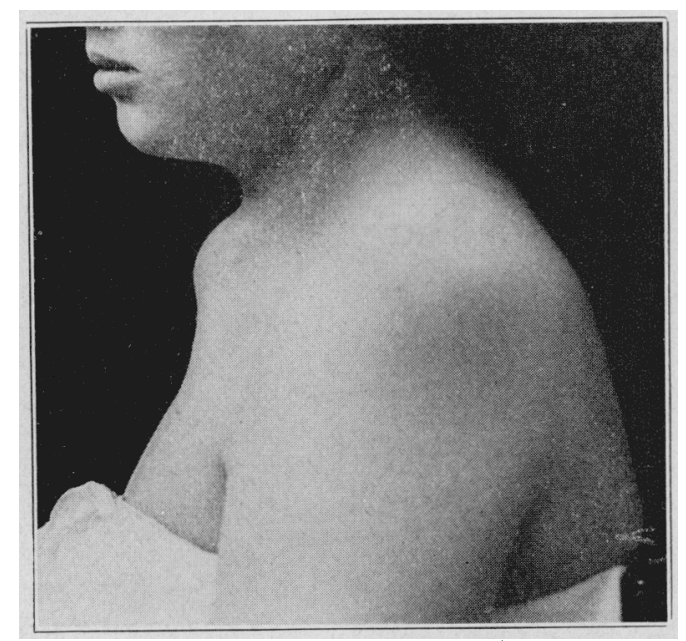

Fig. 1 (Case 3031C2) -Nonmelanotic melano-epithelioma of manulurium of very rapid growth. The patient had two operations before coming to the Clinic.

Case 15 the patient has been free from recurrence for more than nine years following operation for sarcoma.

CAse: 1 (342085).-MIr. J. E. F., aged 47, registered at the Clinic, Nov. 26. 1920, because of a tumor of the chest wall, elsewhere diagnosed sarcoma. About one year before, he had injured his left hand, and was taken to a hospital. While there he had developed night sweats and pain along the right costal border, which had persisted. Later a tumor had appeared, accompanied by: soreness in that area. The patient was otherwise in good condition; he had had no increase in temperature. cough or loss of weight.

A dense, rounded tumor was found in the anterior chest wall. The roentgenogram of the chest revealed elevation of the diaphragm. The urinalyses. including Bence-Jones protein test. Were negative: the Wassermann test was negative. 
Decemher 2, l operatet uncler local and gas intrapharygeal insufflation anesthesia. Segments of the distal ents of the fifth. sixth. seventh, and eighth ribs and cartilages were removed with the tumor mass. An encapsulated abscess arity about $10 \mathrm{~cm}$. in its greatest dimension was found over the costal cartilages at the costal margin. lined with grantulation tissue and with greatly thickened walls: the ribs involved were necrotic and partly broken down. A tear 1.25 $\mathrm{cm}$. long was matle in the plenra; but on account of the positive pressure anesthesia. pneumothorax did not occur. The rent in the pleura was suturerl and the skin flap closed tight. The comvalescence was unerentful.

The pathologist reported chronic inflammation. with osteonyelitis of the rils.

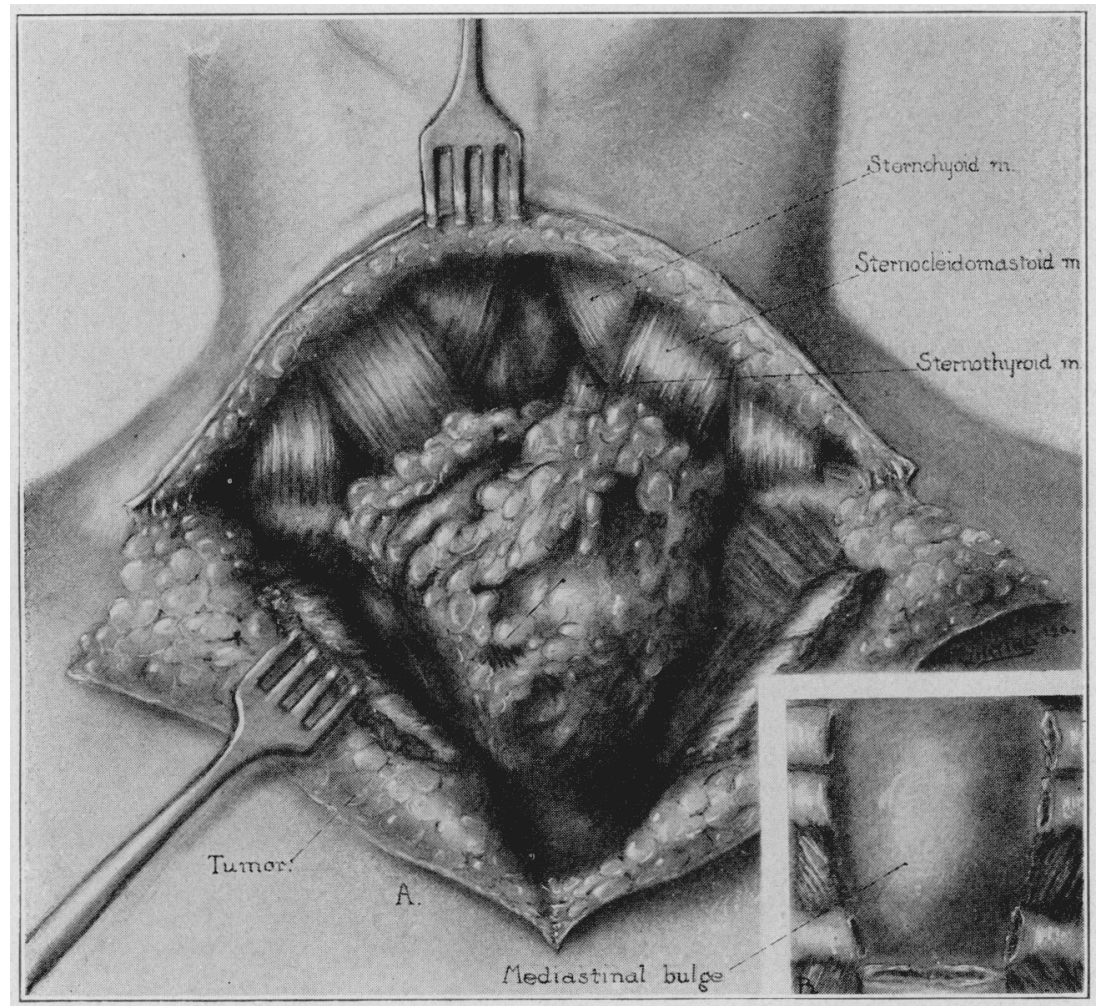

[Fig. 2 (Case 30,3102).-Resection of manul)rium for tumor shown in ligute 1.

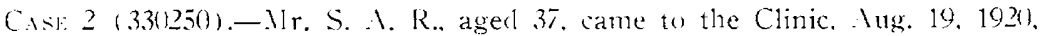
lecause of a recurent growth in the right lower chest wall following an meration elsewhere three weeks liefore for the remoral of a rombl-cell sarcoma. The tumor had been present alont two years. ancl was described by the patient as firmly fixed, tender, and alout the size and shape of an index linger, overlying the rib.

Examination showerl at smooth loulging tumor wer the fifth and sixth rils. 10 or $12 \mathrm{~cm}$, in length. The roentgenogran of the chest, the Wassermam test. and wher clinical himling, were essentially negative. 
September 9 under ether anesthesia I resected about $20 \mathrm{~cm}$. of the sixth, seventh, eighth, ninth, and tenth ribs with the entire thickness of the chest wall except a skin flap. There was no marked respiratory emlyarrassment. The growth was found to have extended through onto the parietal pleura; lut the lung itself was free. The wound was closed tight without drainage.

The patient's general condition was quite satisfactory for two dass; he then developed bronchopneumonia and died the fourth day. Postmortem examination revealed bronchopneumonia of the right lung and congestion and edema of the left.

Cast 3 (316452).-Mr. R. R. C., aged 48. came to the Mayo Clinic, May 19. 1920 , because of a recurring tumor and pain in the right chest wall. In Jannary,

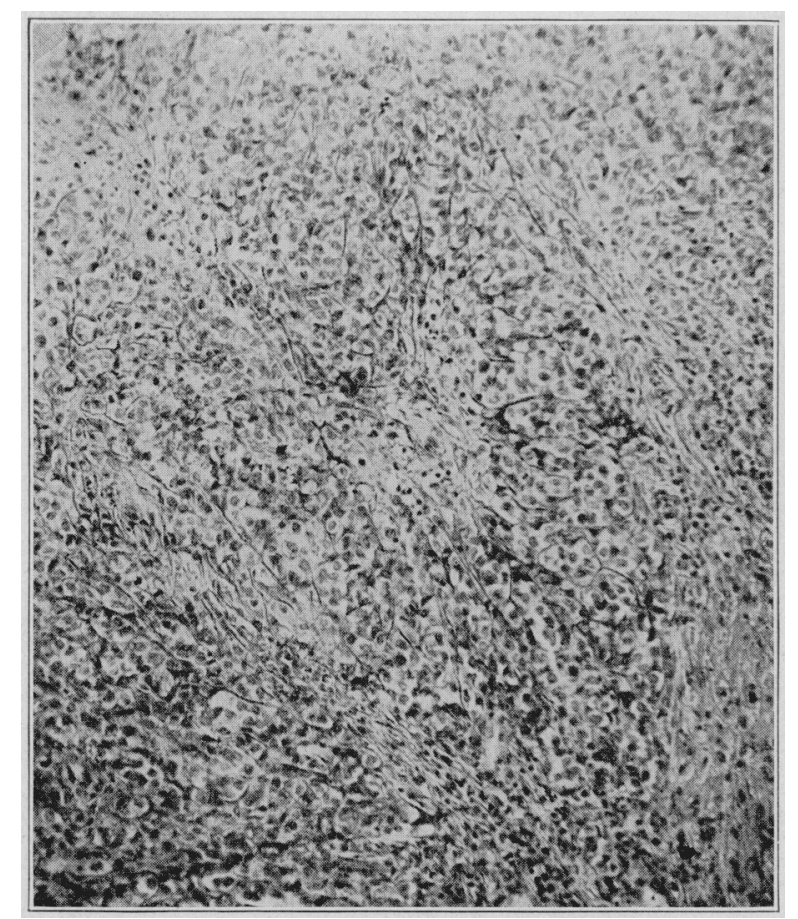

Fïg. 3 (Case 303192).-Photomicrograph of nonmelanotic melano-epithelioma of manubrium.

1916 , he had been struck in the right side of the back by a piece of lumber, and the injured area remained sore for some time. In 1919, the pain recurred. Roentgenograms five months before examination revealed a tumor involving the right seventh rib, which was removed elsewhere with temporary relief from pain. The patient was cachectic and bedridlen.

Examination revealed a tender tumor about $8 \mathrm{by} 12 \mathrm{~cm}$. in the region of the seventh rib below the angle of the scapula.

A two-stage radical resection was attempted. The first stage was performed, May 27, 1920. At the second operation. July 1, the malignant infiltration was found to be so extensive, the skin flap being also extensively inliltrated, and the 
patient in such poor condition that the radical extirpation was not completed. Whe patient was sent home for roentgen-ray and radium treatment. The firal course in the case has not been ascertained.

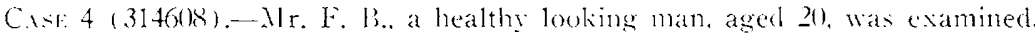
May 4, 1920. Six years hefore he had noticed a silelling of the right anterior portion of the chest just helow the clavicle. which had gradually increased in size and which caused a dull ahe on exertion. lixamination revealed a diffuse

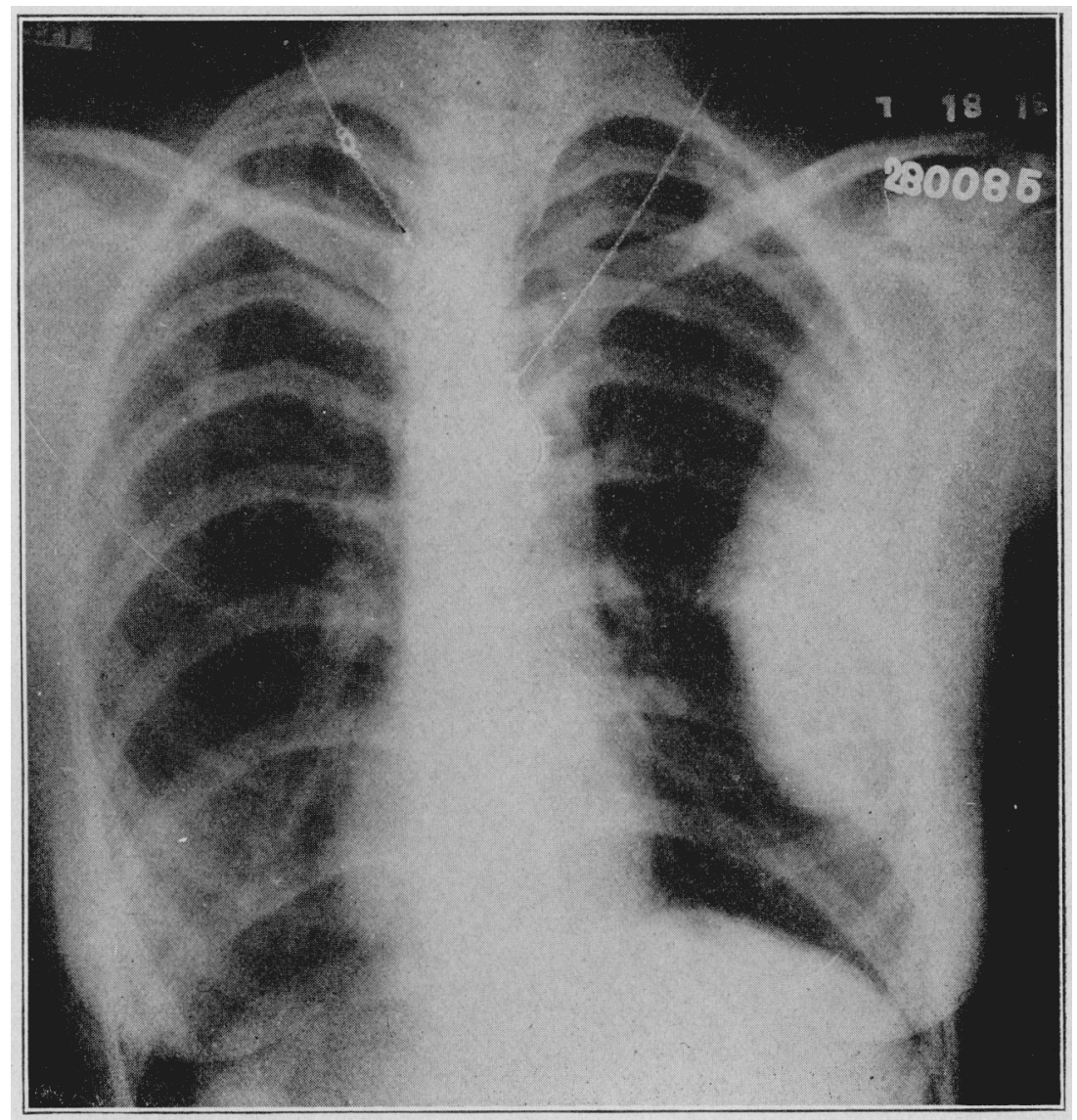

Fig. 4 (Case 280085).-Filoroma encroaching on pleural carity: superficial tumor very slight.

enlargement involving the area of the upper end of the sternum and the first and second ribs. The Wassermann test. roentgen-ray ant Huoroscopic examinations of the chest and sternum were negative.

It operation. May 11, 1920. I resected the sternoclaricular joint and the upper portion of the manubrium. The pathologist reported the contition to be inflammatory, with some periostitis.

There has been no further evidence of neoplasm. 
CAst. 5 (309624).-Mrs. F. M., aged 53. registered at the Clinic, March 20. 1920. She gave a history of having fallen and struck her chest. about seven months before. Four months after the acciclent. she had noticed a swelling in the upper part of the sternum, which increased in size but was not painful.

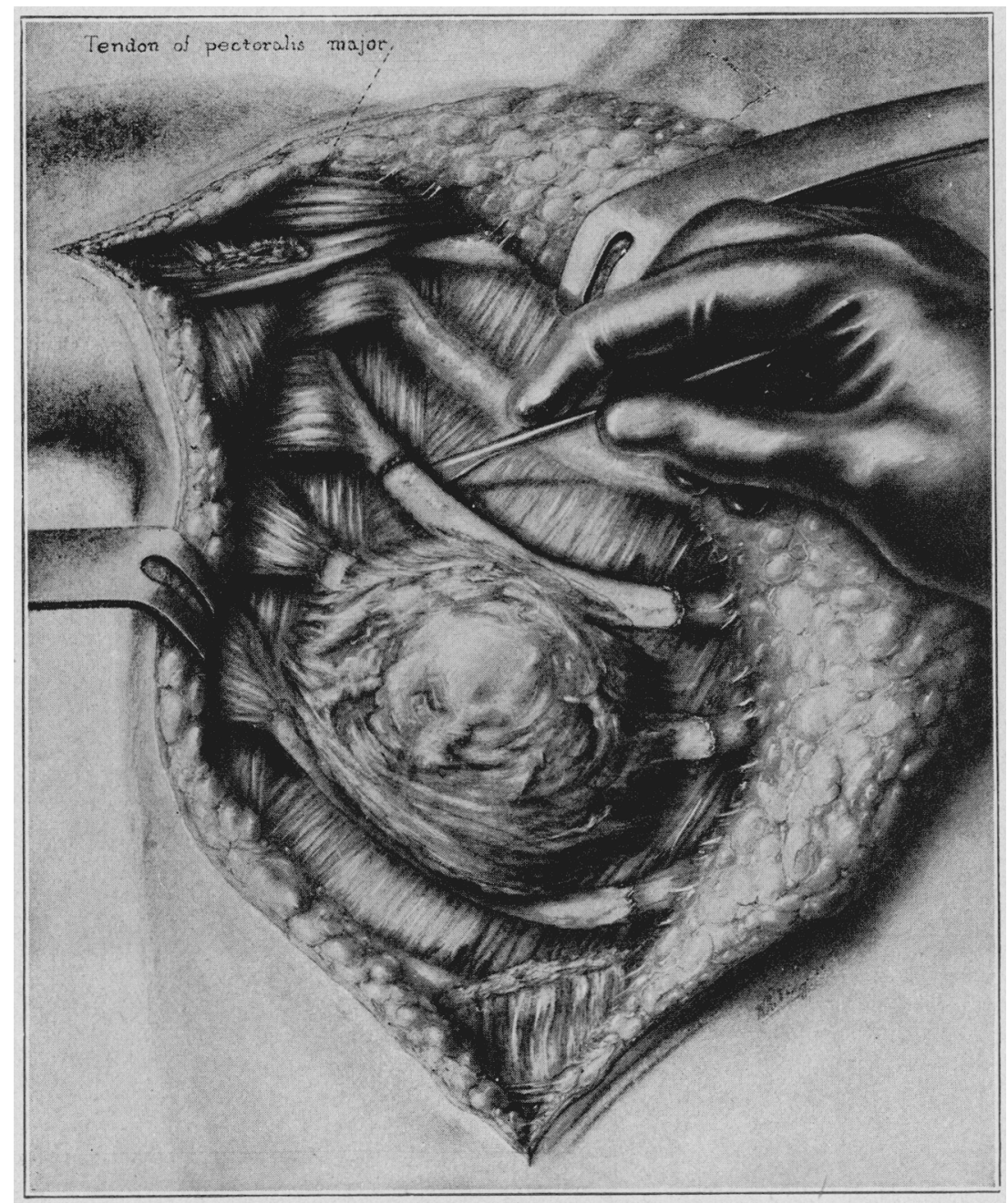

Fig. 5 (Case 280085 ). - Excision of tumur with riss and portion of plenra involved: pectoral musiles have heen removed.

The upper third of the sternum was swollen and the left axillary glanil tender. The roentgenogram was negative.

On exploration. April 13. 1920. I found a hulging at the right sternoclavicular articulation. The manulurium was resected. The pathologist reported periostitis.

There is no eridence of tumor ten months after operation. 
CAst: 6 (313967).-.Mrs. J. J. G., aged 36. came to the Clinic. April 28, 1920. She stated that for the last six months she had had a swelling at the right sternoclavicular joint, and recently, swelling above the clavicle. The pain had apparently been aggravated by an infection of the jaw following extraction of a tooth under ether. She had had some dyspnea the last year, but no loss of weight nor other symptoms. A definite diagnosis of sarcoma had been made elsewhere.

There was an indefinite swelling in the region of the right clavicle. The roentgenogram of the chest showed no evidence of metastasis.

Exploration, May 27, 1920, disclosed apparent involvement of the sternoclavicular articulation only. I resected three fourths of the manubrium. The pathologic examination showed periostitis only.

There is no further evidence of neoplasm nine months after operation.

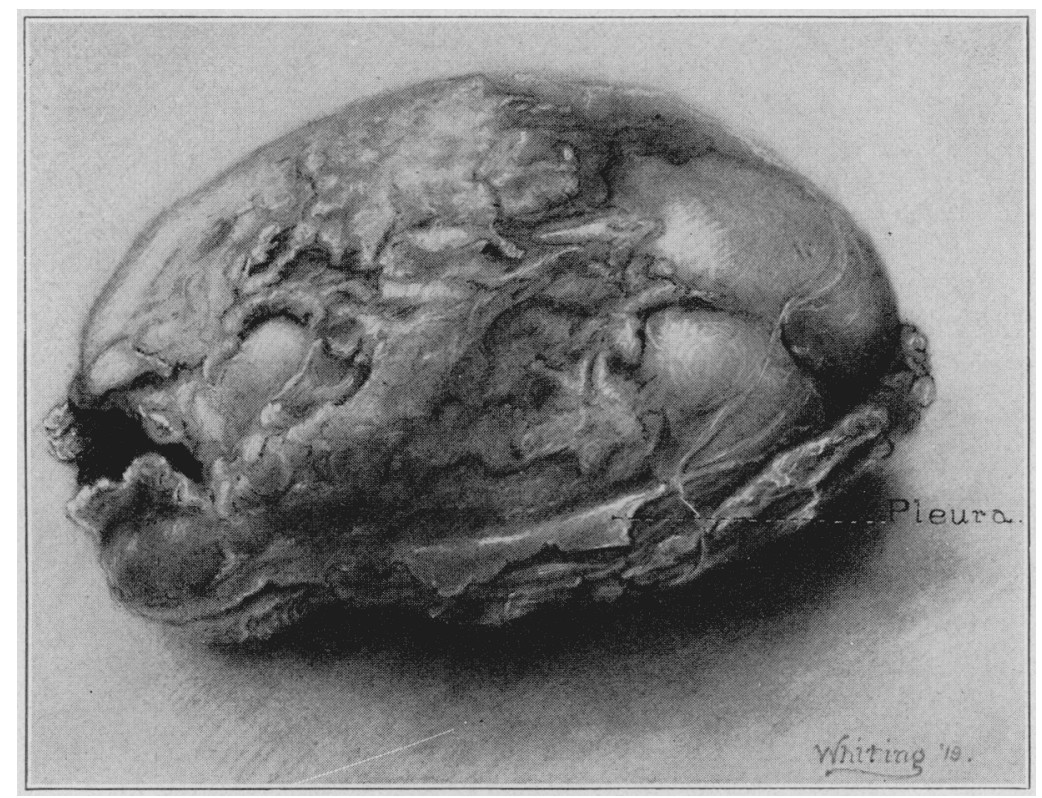

Fig. 6 (Case 280085).-Pleural aspect of tumor with ribs and pleura attached.

C.sil 7 (303102).-Mrs. J. C. W.. Jr., aged 24, registered at the Clinic, Jan. 16 , 1920. because of a recurrent growth at the suprastermal notch. Three years hefore, a small hard lump had appeared in front of the upper part of the sternum. It grew very slowly until fourteen months hefore when following a bruise it rapidly grew to about $6 \mathrm{~cm}$. in diameter, but remained movalle. This and a recurrent growth had been removed elsewhere. Aug. 19, 1919. The pathologist's report at that time was "a tumor bordering on malignancy but not so yet." Coley's toxin had been atministered every two or three days for five or six wecks.

On examination a smooth symmetrically rouncled mass. about 6 or $8 \mathrm{~cm}$. in diameter, could be seen and felt over the suprasternal notch (Fig. 1). The roentgenogram of the chest was negative, and the Nassermann test and the usual urinalyses were negative. 
Operation was performed, Feb. 5, 1920, under ether anesthesia. A necklace incision was made. The tumor mass seemed encapsulated, but attached to the sternum. I removed it in toto, with the inner extremities of the clavicles, the cartilages of the first and second ribs, and the entire manubrium (Fig. 2). The pleural cavities were not opened. The wound was closed tight. Microscopic examination demonstrated a nonmelanotic melano-epithelioma but no involvement of the manulbrium (Fig. 3). The patient's convalescence was uneventful. She had surprisingly little difficulty with movements of the arms or head. During the next three months she received $75.960 \mathrm{mg}$. hours of radium.

Seven weeks after the operation there were numerous shotlike nodules in the skin over the upper sternum. A gland excised at this time from the left

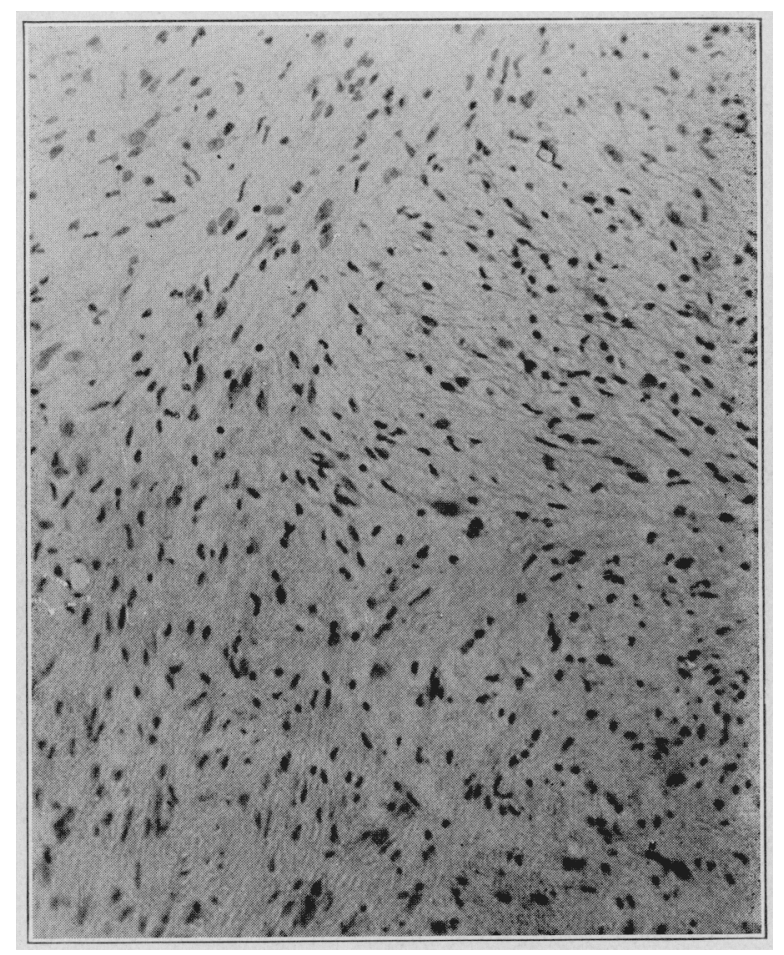

Fig. 7 (Case 280085).-Photomicrograph of fibroma. Patient is symptomfree one year after operation.

axilla showed nonmelanotic melano-epithelioma. The patient died from recurrence, Aug. 17, 1920, six months after operation.

CASE 8 (280085).-Mrs. J. E. P., aged 24, came to the Clinic, July 15, 1919, because of a tumor on the right anterior chest wall, which had been rather indefinite at first, but had increased in size during the last six months.

The patient was frail, anemic, very nervous, and exceedingly apprehensive. The tumor overlay the third, fourth, and fifth ribs, extending outward to the anterior axillary fold. It was hard, smooth, fixed, and slightly tender. The roentgenogram showed that more than one half of the mass projected inside 
the thoracic cavity (Fig. 4). The hemoglobin was 75, the urinary findings normal. The tumor was believed to be either a chondroma or a fibrosarcoma, and a two-stage operation was advised.

At the first operation, July 31, 1919, under ether, I resected the third, fourth, and fifth ribs proximally and distally, and mobilized the tumor. The parietal pleura was thin, showing the lung freely movable underneath. The Halsted operation for amputation of the breast and dissection of the axilla was performed, the axillary glands being enlarged. The lung was sutured to the parietal pleura and the wound closed tightly. The axillary glands proved to be inflamed. The patient was considerably shocked, the pulse reaching 160 two days after the operation. Three hundred culbic centimeters of serous effusion were aspirated the fourteenth day. The tumor mass was removed August 19 under

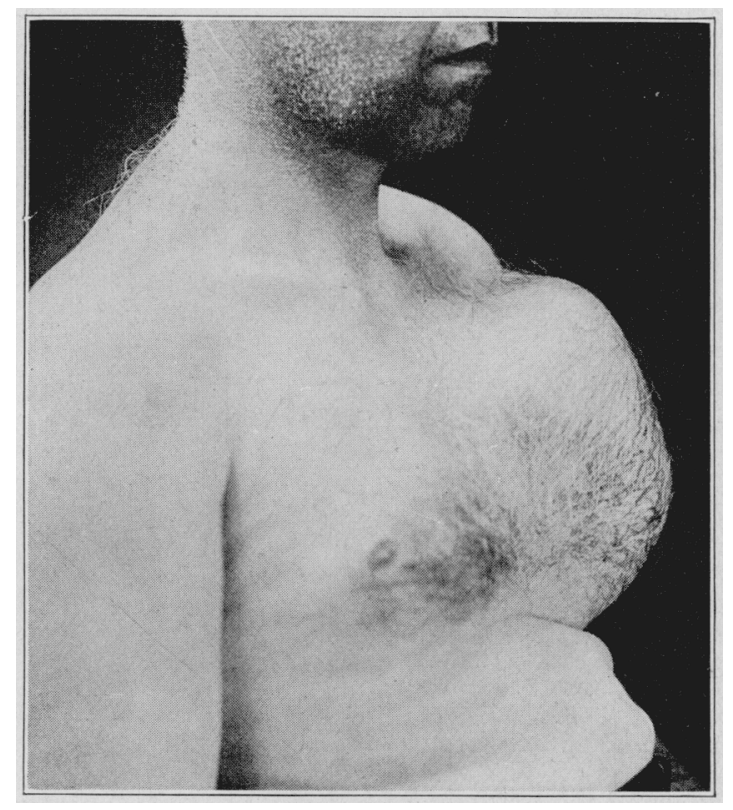

Iïg. 8 (Case 273694).-Chondrosarcoma of fifteen years' duration: rapid growth with severe pain last three months.

light ether anesthesia, by opening up the former incision and cutting the pleura and intercostal tissues widely about it (Figs. 5 and 6 ). The lung was partly collapsed, and the pleural cavity contained about a liter of fluid the color of port wine. There was no respiratory embarrassment nor cyanosis during the operation, which, however, lasted only about fifteen minutes. Microscopic examination demonstrated the tumor to be a fibroma (Fig. 7). A partial collapse of the lung resulted, for which several minor plastic operations were performed, finally completely obliterating the cavity. The patient made a complete recovery.

CASE: 9 (273694).-Mr. C. D. S., aged 43, presented himself at the Clinic, June 5, 1919, with a tumor of the left anterior chest wall, about $20 \mathrm{~cm}$. in diameter. Fifteen years before, he had first noticed a small hard lump near the left nipple which grew very gradually up to three months before examina- 
tion. Since that time the growtl had heen comparatively rapid. Pain, which was first felt in the region involved one year before. had lately been so severe that it interfered with sleep. There had been no noticealle loss of weight.

The tumor covered the larger part of the left anterior chest wall (Fig. 8). It was hard. slightly nodular and fixed. The roentgen ray showed a dense infiltration of the whole left pleural cavity. The right pupil was slightly larger than the left and irregular in outline. The hemoglolin was 69; the Wassermann test and the ordinary urinary tests were negative. The diagnosis was osteosarcoma. and excision was advised.

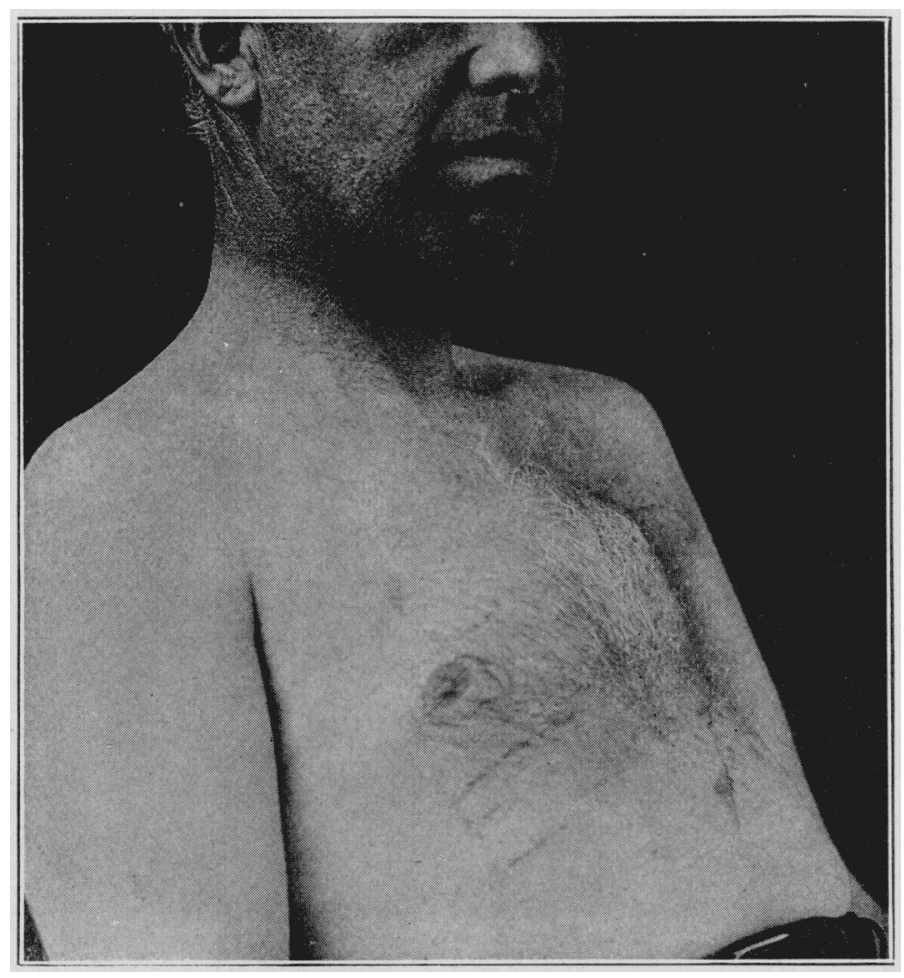

Fig. 9 (Case 27.3694).-Daticnt shown in Figure 8 . lifty-tive days after operation. He died of recurrence thirteen months after operation.

I operated, June 21, 1919. under ether, leginning with an incision as for a Halsted breast amputation. The tumor seemed to be encapsulated. The attachment of the tumor to the chest wall was at least $15 \mathrm{~cm}$. in diameter, involverl the pectoral muscles, and the third, fourth, and fifth ribs. After resection of the rils it was found that the tumor had infiltrated the pleura and pericardium extensively. and apparently also the lung. As much of the tissue as possible was removed. The axilla was dissected and several large bluish soft glands removed. The skin flaps were approximated. Microscopic examination demonstrated the tumor to be an osteochondrosarcoma. The patient was considerably shocked but rallied satisfactorily to warmth and stimulation. The convalescence was uneventful (Fig. 9). 
During the next nine months the patient receiver more than $19.090 \mathrm{mg}$. hours of radium. He gained weight, and the pain disappeared entirely. In Gctober. he reported for examination. Except for several small serum pockets in the skin Haps, the wound was healed and there was no sign of recurrence. In January, a nodule was excised from the axilla and found to be osteosarcoma. The patient died from recurrence. July 15, 1920), thirteen months after operation.

C..s: 10 (269244),-Mr. 11 . S. C.. aged 48, came to the Clinic. April 27. 1919, hecause of pain and a tumor of the right chest wall. He was thin, weak, anemic, irritable, and apprehensive to the point of hysteria. Two and one-half years before he had developed pain in the right chest which was particularly tronlule-

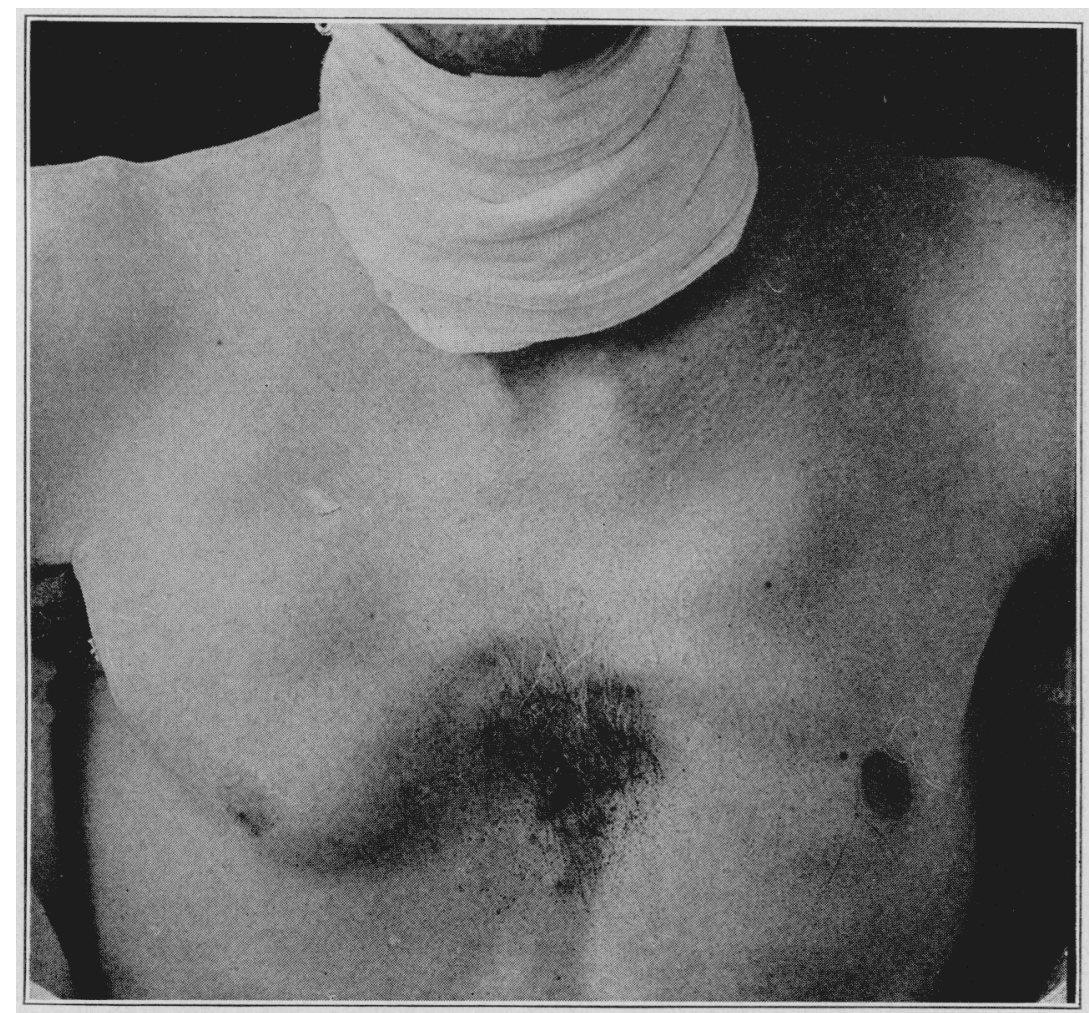

Fig. 10 (Case 269244).--Metastatic adenocarcinoma of lung and breast. primary in suprarenal glands.

some for six weeks. and had persisted more or less since. Following intuenza in October, 1918, the pain had become very sesere. In Feluruary. 1919. a roentgenogram elsewhere revealed a tumor of the right chest wall $5 \mathrm{~cm}$. or more in diameter. At this time the patient hat fever which sulssided following the extraction of several carious teeth. The tumor first became perceptible two months before examination, and grew rapidly. The had recently had some fever and had lost weight.

Examination showed a tumor of the right upper anterior chest walt. $10 \mathrm{~cm}$ in cliameter (Fig. 10). The roentgen ray revealed an extensive intrathoracic 
involvement, lunt the lung appeared not to be involved (Iig. 11). The Wassermatn test was negative: the hemoglobin was 40 : the urine showed normal lindings. The patient refused even to consicler operation until radium treatment had been tried. He received, during Nay and Jume, 25,400 mg. hours of radium, hut the tumor continued to grow, the pain persisted, and the general condition hecame worse rather than better.

lugust 7 and linust 16 under ether anesthesia I performed a two-stage operation in the hope that if the tumor could he removed radium might be of more effect. The tumor was found to be shaped like a clumb-hell, the connecting

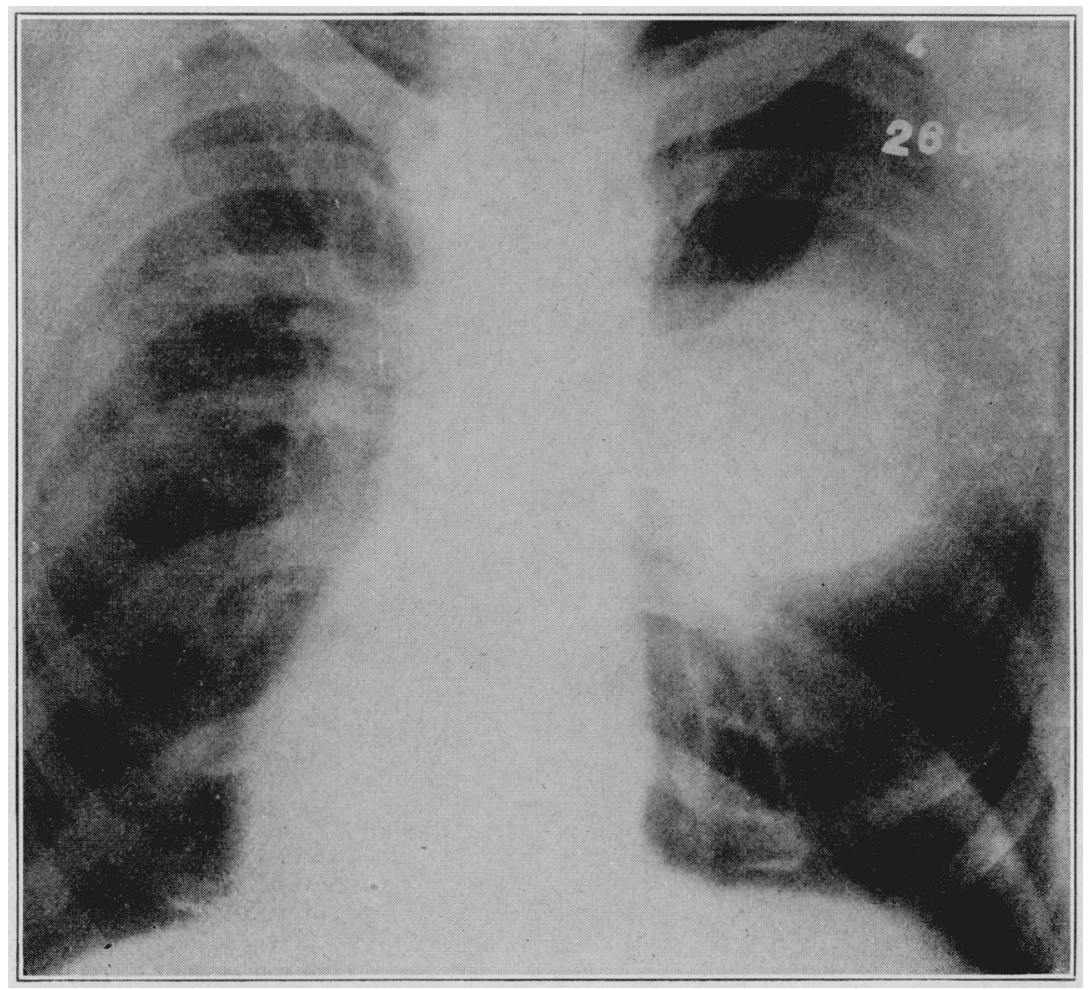

Iig. 11 (Case 269244).-Roentgenogram of aclenocarcinoma of lung and breast shown in Iigure 10 .

mass occupying the third and fourth interspaces, the fourth rib included. The third, fourth, and fifth rils were resected and the tumor enucleated. The pleura was thickened, the tumor seeming to be encapsulated; there was no pneumothorax. The cautery was applied to the base and a skin plastic operation performed to cover the exposed areas. The microscopic diagnosis was adenocarcinoma ( Fig. 12).

The patient developed local recurrence and died six months after operation. Necropsy showed a primary suprarenal growth.

CASE 11 (206257).-Mr. R. O. S, aged 40. presented himself for examination, Aug. 27, 1917. hecause of a growth on the right chest wall which had appeared 
ahout eighteen months hefore and had slowly increased in size. The patient did not give a history of tratma: but he had noted soreness in the area involved six months before the tumor was lirst noterl.

The mass was found to $1 x$ or 12 cm. in cliameter and lirmly fixed to the anterior chest wall. The Wassermann test was negative. I diagnosis of osteosarcoma was made and excision alvised.

Operation was performed Sept. 2. 1917 hy Dr. Rolinson, under ether anesthesia: the tumor and three involved rils. were removed. I tear was male in the pleura in stripping off the tumor. A cleavage plane was followed: but there

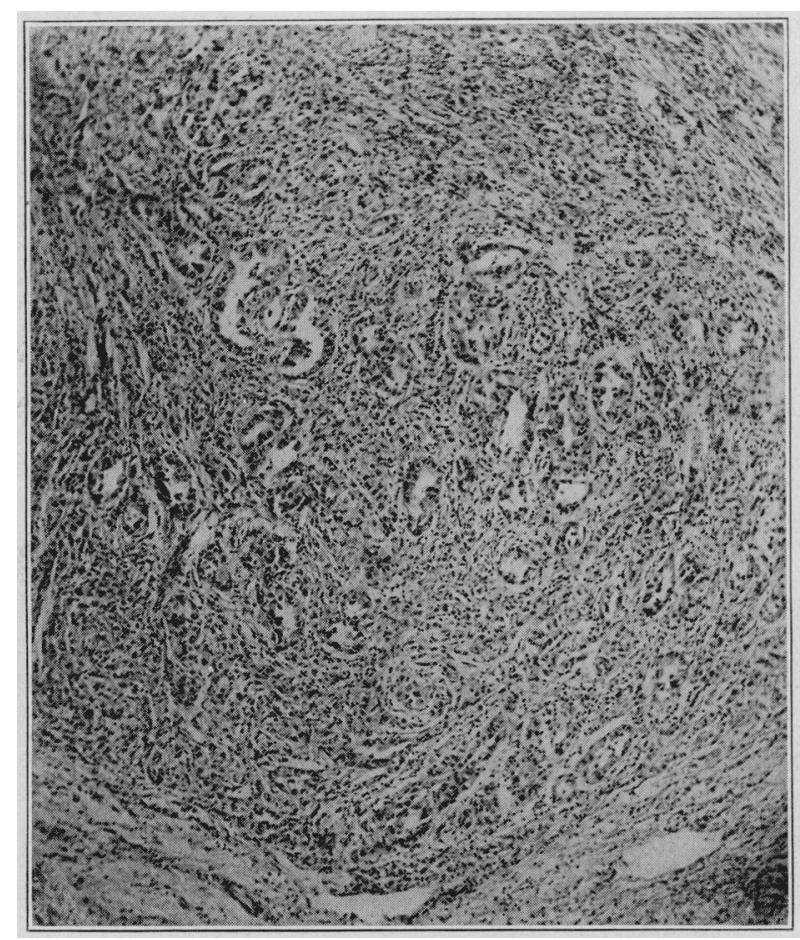

Fig. 12 (Case 269244),-Photomicrograph showing alveolar arrangement of cells in adenocarcinoma.

was question of infiltration of the parietal pleura in one small area. The pathologic report was a rouncl-cell sarcoma. The convalescence was prolonged by infection in the wound, but empyema did not result. The patient harl more than $15,000 \mathrm{mg}$. hours of radium during the six weeks following operation.

In January, 1918, a report was received by letter that the patient had developed weakness and stiffness in the joints four weeks after learing the Clinic; no further report has been received.

CAst: 12 (176942).-Mr. K. F. G. aged 28, eame to the Clinic, Nor. 2, 1916, on account of a tumor of the chest wall. Five years before he had fallen some distance and prolably fractured one of the lower ribs on the right side at 
its sternal end. Two years before examination, he had noted a small mass over this area which grew in a few months to the present size. There had been slight pain and tenderness only during the last few months.

Examination showed a mass at the sixth and seventh right costochondral juncture, which was hard, and immovable, but not tender (Fig. 13). The roentgen-ray examination of the chest, and examinations of urine and of the blood were negative. The diagnosis was chondroma, and operation was advised

Nov. 6, 1916, Dr. Robinson operated, under ether anesthesia. He attempted to dissect the tumor from the pleura, but a rent was made, resulting in a wide, open pneumothorax, which, however, produced no symptoms. The tumor was removed with sections of the fourth. fifth, and sixth ribs, costal cartilages, and edige of the sternum (Fig. 14). Microscopic examination demonstrated the tumor to be a fibroma. During the patient's convalescence a pleural effusion

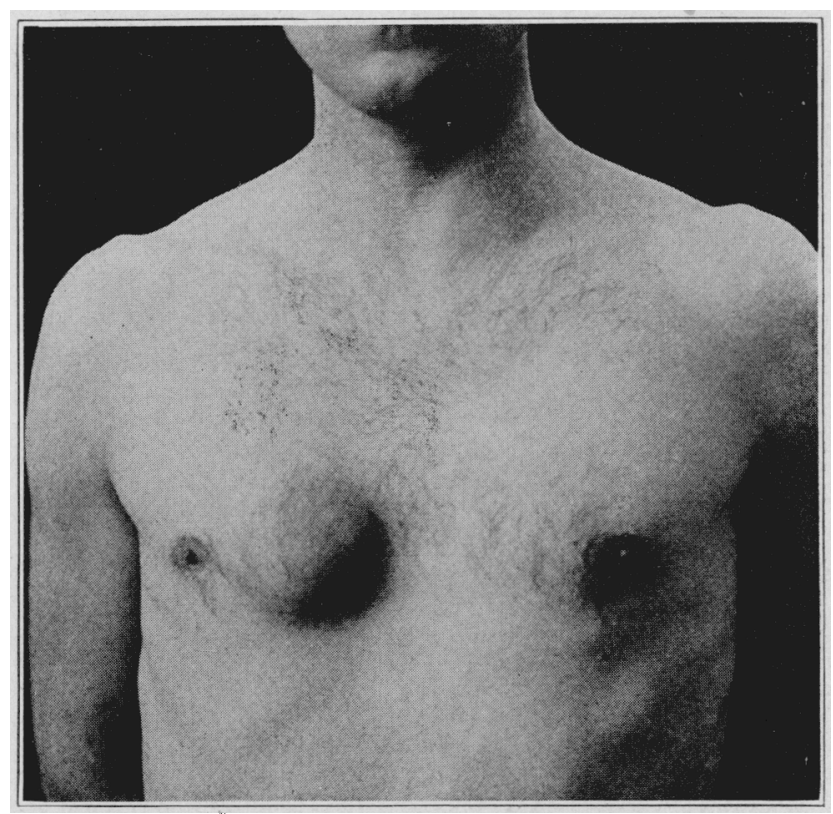

Fig. 13 (Case 176942).-Fïbroma of chest wall, Nor. 2, 1516.

developed, which required four aspirations within the first three weeks. There was no fever.

The patient returned to the Clinic in November, 1919. because of a recurrence. He had been quite well and had been working since a few months after the first operation. A bulging tumor about $5 \mathrm{~cm}$. in diameter was felt, and a circumscribed shadow in the roentgenogram at the right cardiophrenic angle suggested a recurrence.

December 1 and 30. I performed a two-stage operation and found a tumor mass involving the distal end of the fourth rib, the sternum, and the pericardium. The lung was only partly adherent. The tumor mass was removed together with the larger part of the gladiolus and sections of the third and fourth ribs. The tumor lay against the pericardium, but was separated from it without tearing the membrane. The microscopic diagnosis was fibroma. 
Convalescence was uneventful except for bilateral suppurative parotitis (Fig. 15). The patient remained well with no sign of recurrence one year after operation.

CAse 13 (129508).-Mr. E. S., aged 47, came to the Clinic, April 24, 1915, because of a recurrent tumor of the anterior chest wall. Seven years before, a horse had fallen on his chest. Three months later a nodule appeared which grew slowly to about $7 \mathrm{~cm}$. in diameter. The growth was removed elsewhere in 1914 and pronounced a chondroma. Recurrence was noted within three months.

On examination at the Clinic the tumor was found to be 12 or $15 \mathrm{~cm}$. in diameter and firmly fixed to the chest wall; the skin was adherent. There had

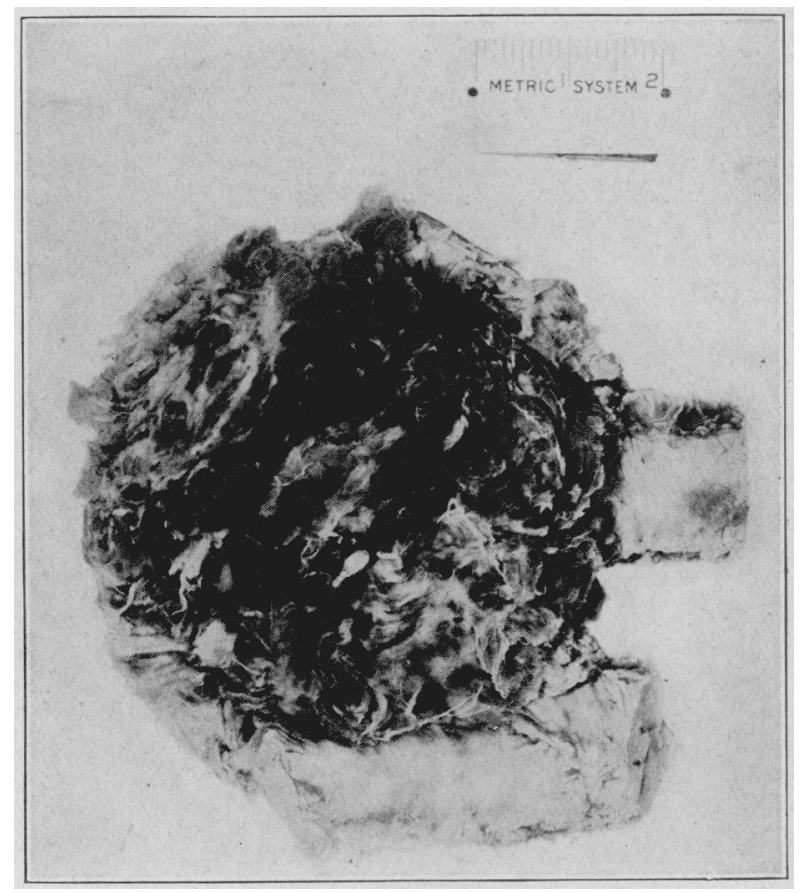

Fig. 14 (Case 176942).-Fibroma shown in Figure 13; involving the fourth, fifth, and sixth ribs, the costal cartilages, and the edge of the sternum.

been cońsiderable pain. A roentgenogram taken diagonally showed no intrathoracic involvement.

The first stage of a two-stage operation was performed, April 30, 1915, by Dr. Robinson, under intratracheal ether anesthesia. The third, fourth and fifth ribs with their cartilages were resected. At the second operation, May 4, 1915, the third, fourth, and fifth ribs were resected and the tumor mass stripped from the parietal pleura without rupturing the pleura. The convalescence was marked by a febrile course lasting about two weeks. The microscopic diagnosis was myxochondrosarcoma.

Dr. Robinson operated for local recurrence in April and in July, 1916, and again in April, 1917, removing the second, third, and sixth ribs and the outer 


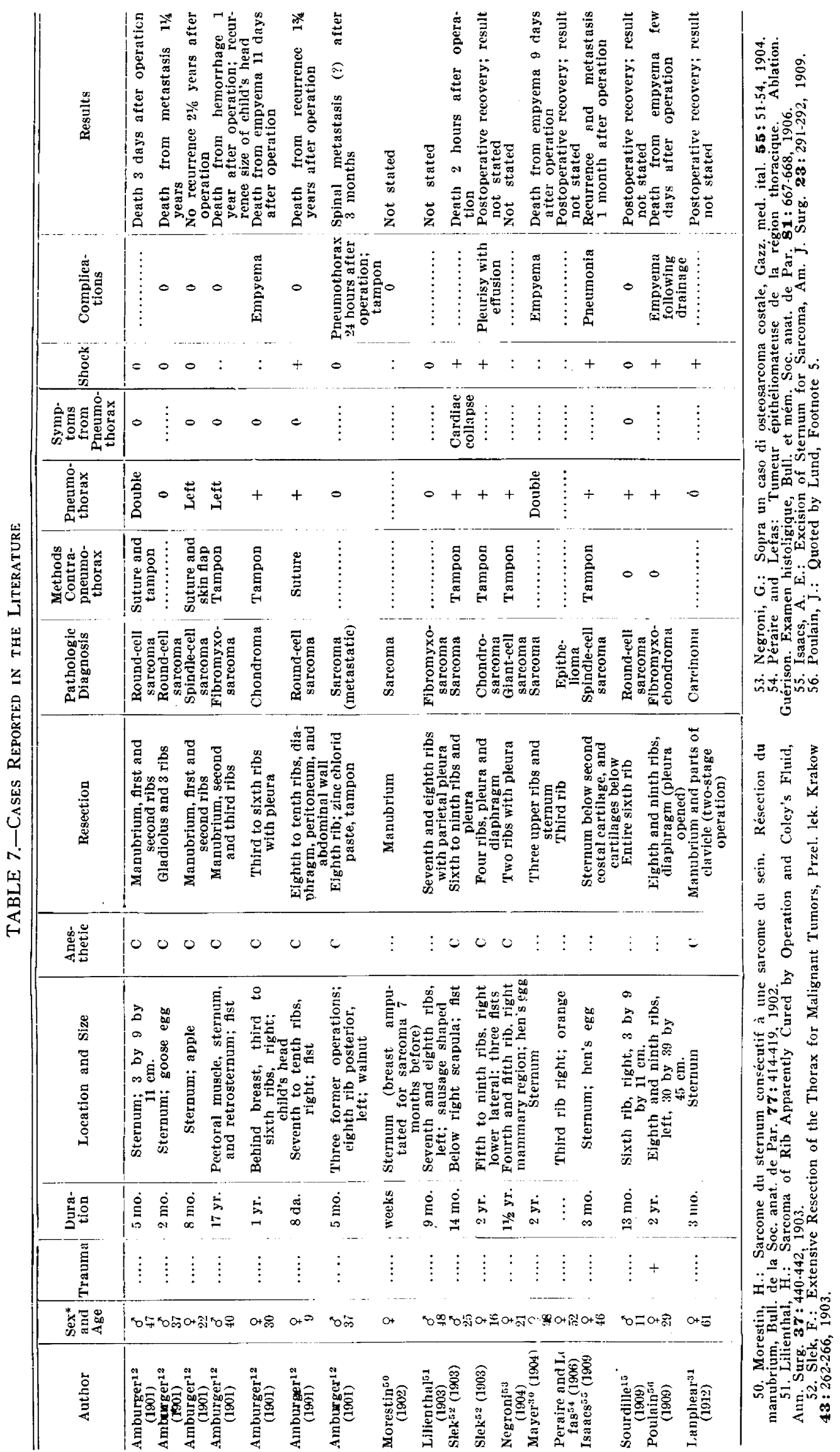

Downloaded From: http://archsurg.jamanetwork.com/ by a Oakland University User on 06/12/2015 


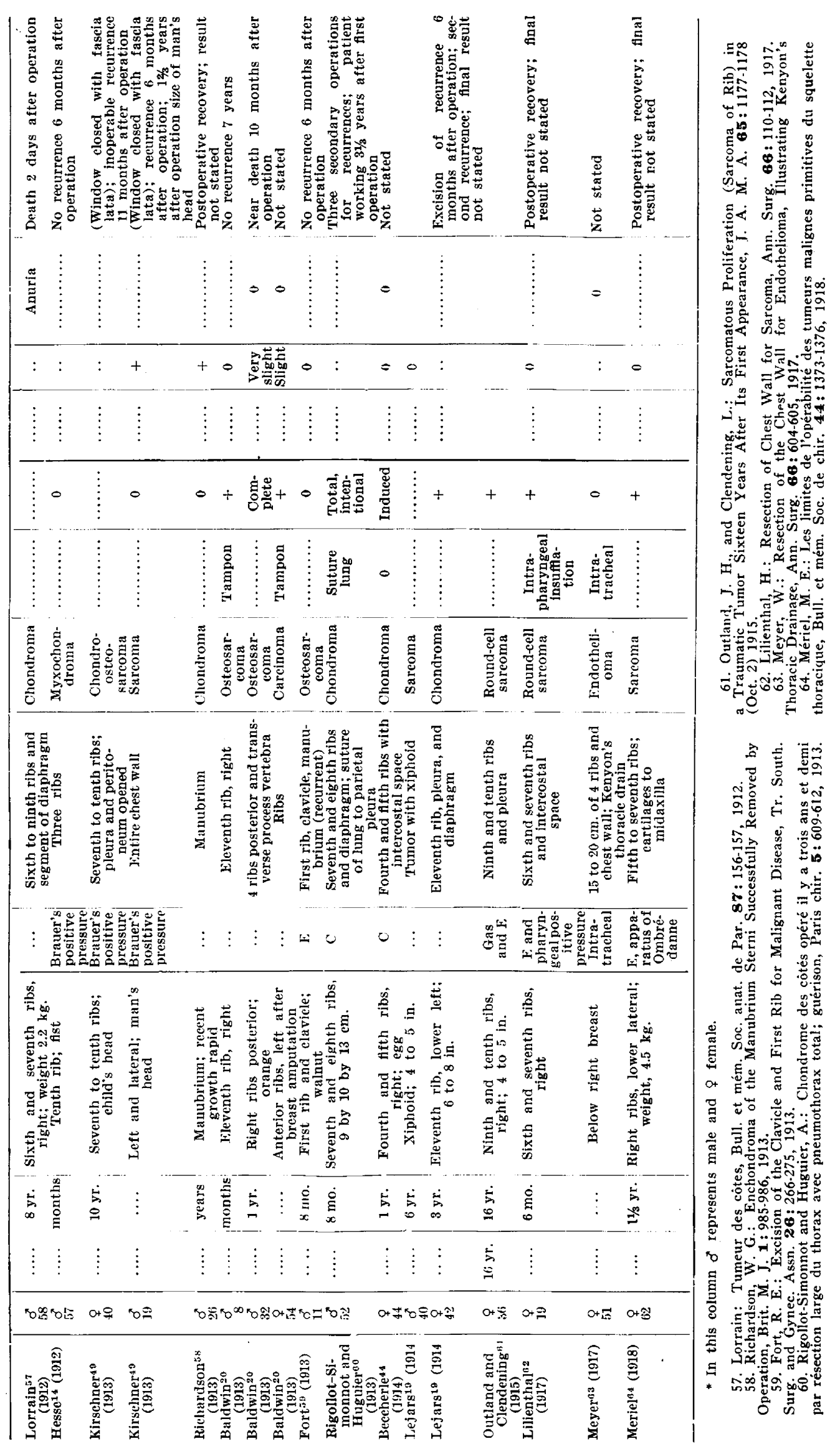


left third of the sternum. In 1916 the patient had five roentgen-ray exposures, and in 1917 two exposures, at intervals of one month. Further roentgen-ray treatment was strongly recommended when the patient was discharged in 1917.

In May, 1919, there was a rapidly increasing recurrent growth for which operation was performed elsewhere in December, 1920. The patient died shortly after operation.

Case 14 (108482).-Mr. P. B., aged 29. came to the Clinic, June 18, 1914, because of pain in the left chest. In 1911 on two occasions five months apart he had sustained rather severe injury to the left chest, probably fracturing a rib at the time of the first injury. Except for constant residual soreness. he had had no symptoms until six months before coming to the Clinic, when he was seized with sudden acute pleuritic pains in the left side. Six aspirations performed at that time were negative, but a month later 5 quarts of bloody

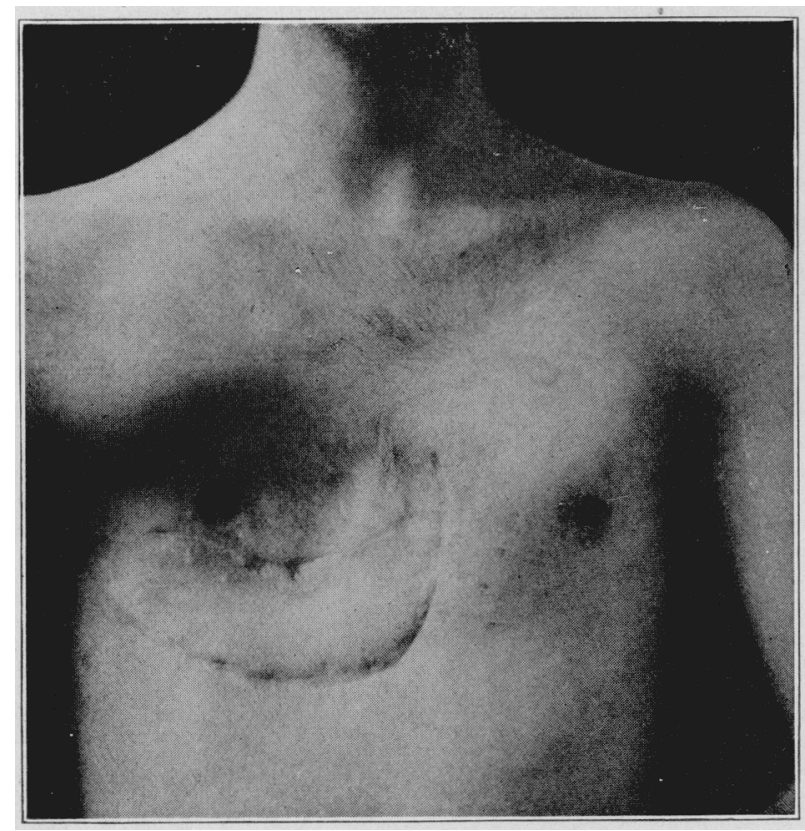

Fig. 15 (Case 176942). - Two and one-half months after operation for recurrent lilsoma involving the fourth rib, the sternum, and the pericardium.

fluid were withdrawn, following which the symptoms cleared up, except for a persistent soreness.

Examination revealed a thickening over the fourth rib anteriorly; which was believed to be callus and thickened pleura. Three months later the patient was reexamined with essentially similar findings. July 2, 1917, he returned with a rard, immovalle tumor seemingly about $8 \mathrm{~cm}$. in diameter, which had developer during the last four or five months into what had been considered a callus. He had lost 30 pounds in weight, and had experienced soreness and occasional sharp pain in the left chest.

Operation was performed, July 19, 1917, 1y. Dr. Rohinson under intratracheal ether anesthesia. The rilss involved were resected. and a tumor mass about 12 
$\mathrm{cm}$. in diameter was dissected from the mediastinum and pleura in what seemed to be a definite tissue plane, but it was broken into, and a small piece removed separately. The pathologic diagnosis was mixed oval-cell and spindle-cell sarcoma. The patient received $6,950 \mathrm{mg}$. hours of radium during 1917 , and later returned repeatedly for roentgen-ray treatment and observation. $\mathrm{He}$ remained in good health, and there was no sign of local recurrence. The large cavity left by the tumor was reduced to a narrow sinus. In October, 1920, he returned complaining of severe pain in the right shoulder and arm. There was no local sign of recurrence; the roentgenogram revealed evidence of an old pleurisy in the chest, and metastasis in the cervical spine.

May 18, the patient again presented himself at the Mayo Clinic. The pain in the arm and shoulder had subsided following radium applied near the spine through a stab wound (treatment elsewhere). He now complained of pain and weakness in the right leg. Roentgen-ray examination revealed no evidence of metastasis in the lumbar spine. Roentgenograms of the cervical spine showed the same conditions as before. His weight was normal and his general condition good.

CASe 15 (52555).-Mr. A. L., aged 63, came to the Mayo Clinic, May 3, 1911, because of a recurrent tumor of the right chest. He had been operated on for a similar growth the previous December. There was no history of pain or loss of weight, and his health otherwise was good.

The roentgenogram revealed a thickened mediastinum.

The patient was operated on May 5; the tumor was excised and the base cauterized. The pathologist reported sarcoma. The patient left the hospital within a few days of operation and was dismissed May 31, with his wound granulating and in good condition. Occasional reports indicated that he was having no further trouble. In the last report, December, 1920, he stated that his health was very good and that there was no sign of a recurrence of the tumor. 